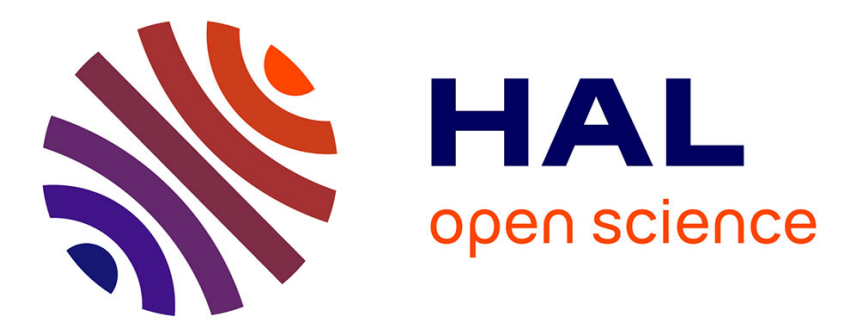

\title{
Reducing CO2 emissions from oil shale semicoke smoldering combustion by varying the carbonate and fixed carbon contents
}

\author{
M. Sennoune, Sylvain Salvador, Michel Quintard
}

\section{To cite this version:}

M. Sennoune, Sylvain Salvador, Michel Quintard. Reducing CO2 emissions from oil shale semicoke smoldering combustion by varying the carbonate and fixed carbon contents. Combustion and Flame, 2011, 158 (11), pp.2272 - 2282. 10.1016/j.combustflame.2011.04.004 . hal-01801118

\section{HAL Id: hal-01801118 \\ https://imt-mines-albi.hal.science/hal-01801118}

Submitted on 1 Jun 2018

HAL is a multi-disciplinary open access archive for the deposit and dissemination of scientific research documents, whether they are published or not. The documents may come from teaching and research institutions in France or abroad, or from public or private research centers.
L'archive ouverte pluridisciplinaire HAL, est destinée au dépôt et à la diffusion de documents scientifiques de niveau recherche, publiés ou non, émanant des établissements d'enseignement et de recherche français ou étrangers, des laboratoires publics ou privés. 


\title{
Reducing $\mathrm{CO}_{2}$ emissions from oil shale semicoke smoldering combustion by varying the carbonate and fixed carbon contents
}

\author{
M. Sennoune ${ }^{\mathrm{a}, *}$, S. Salvador ${ }^{\mathrm{a}}$, M. Quintard ${ }^{\mathrm{b}}$ \\ a Université de Toulouse, Mines Albi, CNRS, Centre RAPSODEE, FRE 3213, Campus Jarlard, F-81013 Albi Cedex, France \\ ${ }^{\mathrm{b}}$ Université de Toulouse, CNRS, IMFT, Allée Camille Soula, F-31400 Toulouse, France
}

Keywords:

Smoldering front

Combustion

Fixed-bed

Oil shale

Semicoke

Carbonate mineral

\begin{abstract}
A B S T R A C T
One technique used to recover oil from ground oil shale, or to burn oil shale semicoke, consists of propagating a smoldering front through a packed bed. One drawback of this technique is that the mineral structure of the shale is decarbonated due to the high temperature of the front. This phenomenon causes $70 \%$ of the $\mathrm{CO}_{2}$ emissions released during such processes. The remaining $30 \%$ result from the fixed carbon oxidation. With the aim of decreasing the front temperature and thus avoiding decarbonation at the front passage, the impact of two parameters was experimentally tested in this work: first, increasing the amount of carbonates, as they may play the role of a heat sink, and second, decreasing the amount of fixed carbon in the medium. It is shown that increasing the amount of carbonates can only decrease the front temperature to $800^{\circ} \mathrm{C}$ but not lower, which is still too high to avoid decarbonation. On the other hand, the front temperature can be decreased enough for decarbonation to be almost completely avoided by reducing the amount of fixed carbon. At the low temperatures reached, almost all the fixed carbon is oxidized, but not all the oxygen transported in the air is consumed by the chemical front. The velocity of the front is consequently decreased.
\end{abstract}

\section{Introduction}

An oil shale is a sedimentary rock that contains a significant proportion of solid organic material embedded in a matrix of fine inorganic minerals. To recover the oil from the shale, its organic portion-termed kerogen-must be thermally decomposed. This thermal decomposition, known as retorting, converts the shale's solid organic material into liquid and gaseous fractions, leaving a solid carbonaceous residue called semicoke. Semicoke is the primary by-product formed in a retort furnace. It is a source of severe environmental pollution and classified as a dangerous waste, because it contains several toxic compounds, such as water-soluble phenols, sulfide sulfur, and polynuclear aromatic hydrocarbons (PAH) $[1,2]$. Its placement into open dumps presents a potential threat of groundwater pollution by polycyclic aromatic hydrocarbons, heavy metals, and phenols via leaching from the semicoke storage due to rain and snow $[3,4]$. In Estonia, for example, solid semicoke is mostly disposed of in open dumps. Approximately 300 million tons of solid semicoke waste is currently present in such dumps [3,5].

At this time, one of the main problems of the oil shale industry is to find an effective treatment for semicoke. Combustion with heat recovery is one of the solutions, but it is the source of a large

\footnotetext{
* Corresponding author. Fax: +33563493242.

E-mail address: mohamed.sennoune@mines-albi.fr (M. Sennoune).
}

quantity of $\mathrm{CO}_{2}$ emissions resulting from decarbonation of the mineral matrix.

Smoldering in porous media consists of propagating a combustion front, fed with some oxygen, through a packed bed of granular solids. It is a complex process, due to the large number of thermochemical and physical subprocesses involved [6]. There are numerous examples of this phenomenon-also known as filtration combustion-both in the natural world and in industry. It has been studied extensively in the literature. Among the many published papers, one may refer to the pioneering works of Aldushin and Seplyarsky [7], which studied the propagation of one-dimensional combustion waves in a porous medium. The work of Ohlemiller [6], Schult et al. [8], and Oliviera and Kaviani [9] are important references for the physical processes involved and their modeling.

There are two basic configurations for fixed-bed combustion, depending on the directions of the air and fuel flows: co current (or forward) combustion, and countercurrent (or backward) combustion [10]. Co current combustion is the most energy-efficient mode of propagation since, in this configuration, the oxidizer flows through the chemical front and the transported energy is used to preheat the fuel and porous matrix ahead of the chemical front [6-11].

Schult et al. [8] studied smoldering propagation in the context of forced forward combustion. Two different traveling waves were identified: reaction-leading and reaction-trailing waves. Both front structures have two layers propagating with constant, though not 
necessarily equal, velocity. These are the fixed carbon combustion layer and the heat transfer layer. They are separated by a region of constant high temperature called later a plateau. The reaction leading structure prevails when the combustion layer-or chemical front-travels faster than the heat transfer layer or thermal front. The present work deals with this most commonly encountered structure.

The particular case of oil shale smoldering has recently been studied by Martins et al. [12,13]. Oil shale conversion can be divided into five major phases:

- Water evaporation.

- Release of volatile mater-or devolatilization-which includes light (incondensable) gases and (condensable) heavy oil. The solid that is left after this phase is called fixed carbon (FC).

- Simultaneous direct oxidation of part of the organic matter, called low-temperature oxidation (LTO).

- Ignition and burning of the fixed carbon, which is also called high-temperature oxidation (HTO). This reaction is essential in the process, as it supplies the thermal energy required to propagate the front. When the front temperature is high enough $\left(>800^{\circ} \mathrm{C}\right)$, this reaction controls the fixed carbon oxidation layer velocity. In fact, the carbon oxidation and oxygen utilization are now complete, so the reaction stoichiometry determines the progress of the chemical front.

- Decomposition of carbonate minerals entering the oil shale composition. These minerals are $\mathrm{CaCO}_{3}$ and $\mathrm{MgCO}_{3}$ and will be referred to as $\mathrm{CaCO}_{3}$ in this work.

It was also shown that $\mathrm{CO}_{2}$ from decomposition of carbonates represents $70 \%$ of the total $\mathrm{CO}_{2}$ emissions, the rest resulting from fixed carbon oxidation. Therefore, there is strong environmental interest in avoiding medium decarbonation at the passage of the smoldering front.

\subsection{Factors influencing the plateau temperature-energy balance approach}

Generally speaking, the plateau temperature is known to be dependent on the amount of fixed carbon in the porous medium and on the fraction of oxygen in the fed gas. It does not depend on the fed air-flow rate when enough oxygen is provided for selfsustained propagation.

The plateau temperature can be calculated from an energy balance on the two layers (chemical front and thermal front). In the case of a medium that does not contain carbonates, and assuming that all the $\mathrm{FC}$ is oxidized to $\mathrm{CO}_{2}$, the plateau temperature can be calculated simply, as described in Elayeb [14], who established that

$T_{\mathrm{p}}=\frac{(1-\varepsilon)\left(x_{\mathrm{FC} \mathrm{fu}}-x_{\mathrm{FC} \mathrm{res}}\right) \Delta H_{\mathrm{FC}}}{\widehat{C}|\delta-1|}$,

where

$\widehat{C}=\varepsilon C_{\mathrm{g}}+(1-\varepsilon) C_{\mathrm{S}}$.

This expression shows the dependence of the plateau temperature $T_{\mathrm{p}}$ on $\delta$. The case $\delta=1$ would lead to a plateau temperature tending to infinity. The plateau temperature decreases rapidly when $\delta$ moves away from one.

In the case of oil shale or semicoke, FC is actually first oxidized into $\mathrm{CO}$, but $\mathrm{CO}_{2}$ is also observed in the produced gas. No flaming occurs in the smoldering process, although recent papers [14] have shown theoretically that, under certain circumstances, some porescale local processes occur that involve $\mathrm{CO}$-to- $-\mathrm{CO}_{2}$ oxidation in the bulk gas phase. Whether this should be termed "flaming" is debatable. Since our experiments cannot provide any information on this discussion (given the scale involved), we have left this question open at this point. On the other hand, some decarbonation of the mineral matrix does occur. These two phenomena affect the plateau temperature and make it more complex to calculate. Indeed, the oxidation of $\mathrm{C}$ into $\mathrm{CO}$ consumes $2 \mathrm{~mol}$ of $\mathrm{C}$ for $1 \mathrm{~mol}$ of $\mathrm{O}_{2}$. This leads to a rapidly advancing chemical front and, in addition, means that the reaction is less exothermic than the oxidation of carbon to $\mathrm{CO}_{2}$. For these two reasons, the oxidation of $\mathrm{C}$ into $\mathrm{CO}$ leads to lowtemperature fronts. Conversely, the direct oxidation to $\mathrm{CO}_{2}$ leads to slow chemical fronts and high exothermicity, resulting in a hightemperature front.

A thermal balance for these mechanisms is proposed in this work. It makes it possible to estimate the plateau temperature. Details of the calculation are given in Appendix A. The plateau temperature is expressed by Eq. (A.14), which we recall here:

$T_{\mathrm{p}}=\frac{\dot{m}_{\mathrm{CaCO}_{3}} \Delta H_{\mathrm{CaCO}_{3}}+\dot{m}_{\mathrm{FC}} \Delta H_{\mathrm{FC}}}{\dot{m}_{\mathrm{res}} C p_{\mathrm{res}}-\dot{m}_{\mathrm{g}} C p_{\mathrm{g}}}+T_{\mathrm{amb}}$

Let us examine the implications of this theory.

First, we consider the impact of $\mathrm{FC}$ and $\mathrm{CaCO}_{3}$ concentrations. Figure 1 plots the plateau temperature calculated from this approach as a function of the concentrations of $\mathrm{FC}$ and $\mathrm{CaCO}_{3}$. It is assumed here that all the $\mathrm{FC}$ is oxidized and all the $\mathrm{CaCO}_{3}$ is decarbonated. It must be noted that the cases with low FC amounts and high $\mathrm{CaCO}_{3}$ content lead to unrealistic front temperatures. We see from these results that the amount of FC has a tremendous impact on the plateau temperature. A change of $1 \%$ in FC concentration leads to a change of approximately $600{ }^{\circ} \mathrm{C}$ in the plateau temperature. When the amount of decarbonated $\mathrm{CaCO}_{3}$ is increased from $0 \%$ to $30 \%$, the plateau temperature is significantly affected: it decreases by $900^{\circ} \mathrm{C}$. This shows that the impact of the $\mathrm{CaCO}_{3}$ content on the plateau temperature is highly significant.

As indicated, there is also a strong potential impact of the fraction of FC oxidized to $\mathrm{CO}-$ called frCO. We have plotted the plateau temperature versus this parameter in Fig. 2 . The results show that this parameter may theoretically affect the plateau temperature by more than $2000^{\circ} \mathrm{C}$. In practice, as will be shown later in this paper, frCO is observed to vary between 0.19 and 0.35 . The figure indicates that this leads to a plateau temperature change of more than $300^{\circ} \mathrm{C}$. It is clear that this parameter-which, in practice, is not a controlled parameter but an observed parameter resulting from a complex chemistry that is difficult to model-has a very strong influence on the plateau temperature.

To conclude, based on a thermal balance development, we have shown that not only the fixed carbon content but also the $\mathrm{CaCO}_{3}$ content and frCO parameter greatly influence the plateau temperature.

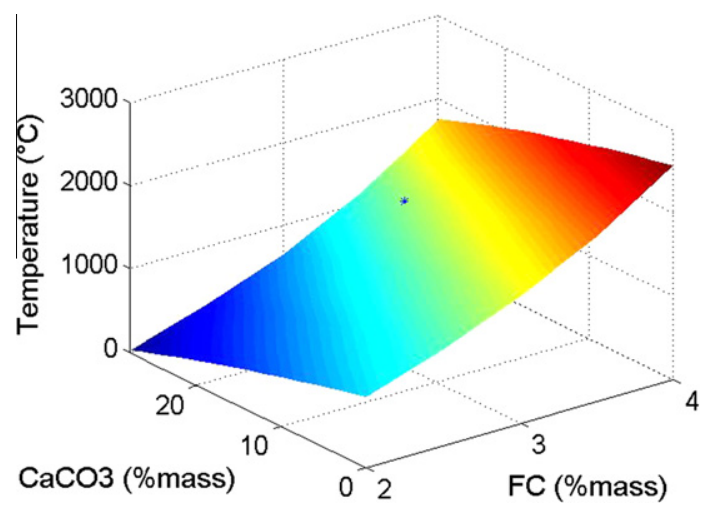

Fig. 1. Impact of $\mathrm{FC}$ and $\mathrm{CaCO}_{3}$ amounts on the plateau temperature as calculated from an energy balance on the two layers (case with $\mathrm{frCO}=0.3$ ). ${ }^{*}$ corresponds to conditions of the reference case in this work. 


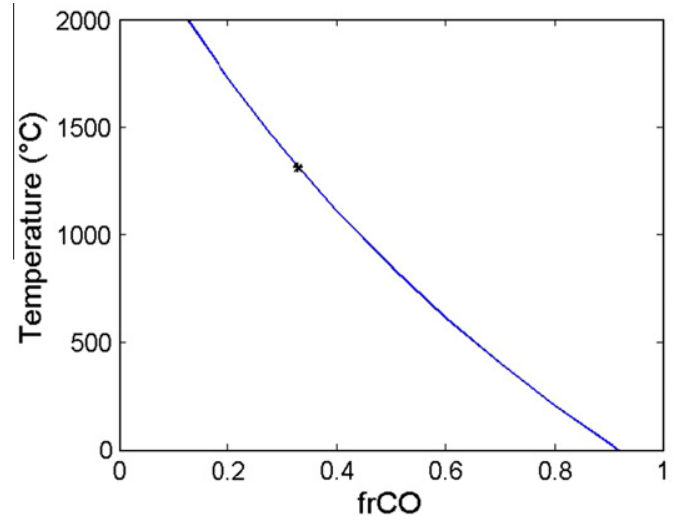

Fig. 2. Impact of the fraction of fixed carbon oxidized to $\mathrm{CO}$ on the plateau temperature (case with $\mathrm{FC}=3.48 \%$ and $\mathrm{CaCO}_{3}=22.4 \%$ ). ${ }^{*}$ corresponds to the reference case in this work.

1.2. Literature about oil shale (OS) and semicoke (SC) combustion and the impact of medium composition

It has been recognized in the literature that both the fuel properties and the process conditions affect the combustion mechanisms, altering the heat generation, heat transfer, and reaction rates in a complicated manner [15]. Only a handful of experimental works on co current combustion have been carried out until now (more recently Pironi et al. [16], Vantelon et al. [17], Zhou et al. [18], Fang et al., [19], Changkook et al. [20]).

The combustion of oil shale semicoke has recently attracted the interest of many researchers. Miao et al. [21], Jiang et al. [22]using thermogravimetric analysis-studied the ignition mechanism of semicoke and the effect of pyrolysis temperature and heating rate on its combustion. The behavior of sulfur compounds during the thermo-oxidation of semicoke oil shales and their different mass ratio mixtures was studied by Kaljuvee et al. [23]. Wang et al. [24] investigated the interactions between oil shale and its semicokes during cocombustion processes and thoroughly evaluated the behavior of cocombustion. Arro et al. [25] compared different combustion technologies and proposed that semicoke and oil shales should be burnt together in a circulated fluidizedbed boiler (CFBB).

Vantelon et al. [17] made an experimental study of the forward combustion of tire pieces mixed with refractory briquettes. They showed that, for a tire mass fraction lower than $50 \%$, the chemical front was unstable and the results were difficult to reproduce. In the same context, Pironi et al. [16] studied the influence of fuel saturation-in a mixed bed of coal tar and sand-on the average smoldering velocity and peak temperatures. Results from tests at various fuel saturation levels demonstrate that ignition and selfpropagation can be achieved at saturation levels as low as $10 \%$, and they also show a nonlinear dependence of the peak temperature on saturation. These results also indicate that, as saturation increases, the smoldering velocity decreases in a roughly linear fashion, which confirms that, for this saturation range (and air flux), the reaction is oxygen-limited. To summarize this review, no specific work was found in the literature about the influence of the OS or SC composition on the smoldering front temperature. Neither was any work found on the determination of the level of decarbonation in a porous medium after the propagation of a smoldering front.

Based on this literature survey, and the theoretical material described in Appendix A, the objectives of this work are to study the effect on the temperature of a smoldering front of two parameters involved in the composition of the porous medium bed: (i) the carbonate-minerals fraction and

(ii) the fixed carbon fraction.

In particular, we want to answer the question: can we propagate a smoldering front without decarbonation of the $\mathrm{CaCO}_{3}$ mineral? Indeed, if this were possible, one could consider the alternative of mixing OS or SC with carbonates or sand prior to processing them, in order to decrease the combustion temperature and thus avoid decarbonation.

It is also expected that this work will allow us to determine experimental values for the frCO parameter, which was shown to play an important role in the process.

Semicoke particles were chosen to prepare the porous medium for our experiments. The reason for this choice is given in the next section. The semicoke for this work was prepared by retorting Timahdit Oil shale, a deposit found in the Atlas Mountains of Morocco. The combustion experiments were carried out by mixing semicoke, sand, and carbonate minerals. This enabled us to vary the FC and carbonate mineral amounts independently.

In the present work, SC was chosen for all the experimental work because it presents a number of advantages as compared to OS:

(i) Performing experiments with SC instead of OS facilitates the interpretation of the results, because the LTO reactions and the devolatilization reaction no longer occur when SC is used. These reactions are avoided in semicoke media because the only organic matter is fixed carbon, which only undergoes HTO. As detailed further in the paper, a mass balance based on flue-gas analysis is necessary for the determination of the fraction of $\mathrm{CaCO}_{3}$ that is decarbonated and of the fraction of $\mathrm{FC}$ that is oxidized to $\mathrm{CO}$, denoted frCO. If the medium only contains $\mathrm{FC}$ and $\mathrm{CaCO}_{3}$, then only $\mathrm{N}_{2}, \mathrm{O}_{2}$, $\mathrm{CO}$, and $\mathrm{CO}_{2}$ are present in the flue gas, which is free from volatile matter. In contrast, when oil shales are used, noncondensable gas and oil are produced. Oil is probably condensed downstream of the chemical front. It can form a bank that induces fluctuations in the bed pressure drop and fed air-flow rate at the front, thus requiring a more complex analysis.

(ii) When OS is used, it has been shown [12] that part of the fed $\mathrm{O}_{2}$ is consumed by LTO reactions, i.e., direct reaction of $\mathrm{O}_{2}$ with the OS organic fraction. This make it more complicated to establish the mass balance. Because of this reaction, which is complex to describe, Martins et al. [12] did not succeed in balancing $\mathrm{O}_{2}$ species for their experiments with OS.

The DSC analysis performed by Martins et al. [12] indicated that the devolatilization reaction has such a small reaction enthalpy that it cannot be determined. It is admitted that this reaction has no thermal impact on the chemical front propagation. Nevertheless, the LTO reactions have a high reaction heat and consume some oxygen. Therefore, these reactions can introduce a difference between oil shale and semicoke smoldering.

\section{Experimental devices and procedure}

\subsection{Semicoke preparation and characterization}

The OS used in the work originates from the deposit of Timahdit in Morocco. It is from the same batch as the one used in [12,13]. The oil shale was received as hard dark gray blocks, typically 10$20 \mathrm{~cm}$ long, and $10-20 \mathrm{~cm}$ wide, and several $\mathrm{cm}$ thick. They were crushed using a rock-grinding device in order to reduce their size. A particle size range of $500-2000 \mu \mathrm{m}$ was selected, and large particles were ground and sieved again. This particle size range 
was retained for all characterizations and experiments reported here.

\subsubsection{Retorting furnace}

The retorting furnace used to prepare semicoke from the oil shale was a batch fixed-bed. It consisted of a stainless steel reactor externally heated by an electric rig furnace. The pyrolysis heating rate and final temperature were controlled. A quantity of $2140 \mathrm{~g}$ of crushed oil shale sample was placed in four drawers with $2 \mathrm{~cm}$-thick layers to facilitate heat transfer inside each layer. The reactor was continuously swept by $2 \mathrm{~L} \mathrm{~min}^{-1}$ at STP of $\mathrm{N}_{2}$, which was enough to avoid air leakage inside the furnace and to flush the VM out of the furnace to the condensation unit. It was heated to $550{ }^{\circ} \mathrm{C}$ at a constant rate of $5^{\circ} \mathrm{C} \mathrm{min}-1$, maintained at this temperature for $1 \mathrm{~h}$, and then cooled by turning the furnace off. The chosen temperature of $550{ }^{\circ} \mathrm{C}$ is high enough to induce degradation of organic matter to $\mathrm{FC}$, and low enough to avoid decarbonation of the mineral matrix. The heating rate was imposed by the furnace and the sample mass to be heated. The duration of $1 \mathrm{~h}$ was found necessary to achieve a high degradation level of organic matter. The gases and vapor leaving the retort were cooled at $4{ }^{\circ} \mathrm{C}$ to condense oil and water using a heat exchanger placed at the exit of the retorting furnace. An activated carbon filter was placed at the exit of the exchanger to remove odor.

\subsubsection{Horizontal tube furnace (HTF)}

An HTF was used to characterize the initial oil shale, the prepared semicoke, and the solid residue after combustion. This reactor has been described in detail in [13]. It consists of a 70-mm i.d. horizontal quartz tube heated electrically and swept by atmospheric air, which is preheated before reaching the middle of the tube. A 2-mm-thick layer of sample was placed in a quartz spoon at the end of a quartz handle and in the cold zone of the reactor, outside the electrical furnace. The atmosphere was then set to $\mathrm{N}_{2}$ or to air, depending on the test (pyrolysis or oxidation), with a continuous flow rate of $2 \mathrm{~L} \mathrm{~min}^{-1}$ at STP. The spoon was then pushed up to the middle of the furnace, where the temperature was controlled.

The amount of volatile matter was determined by measuring the solid decomposition at $550{ }^{\circ} \mathrm{C}$ after 7 min under inert atmosphere. To determine the amount of FC, the test was performed at $550{ }^{\circ} \mathrm{C}$ for 20 min under air, subtracting the amount of volatile matter. At $900{ }^{\circ} \mathrm{C}$ under oxidizing atmosphere for $10 \mathrm{~min}$, the obtained mass loss corresponded to the release of volatile matter, of fixed carbon, and of $\mathrm{CO}_{2}$ produced by decarbonation. The amount of $\mathrm{CO}_{2}$ produced by decarbonation was determined by difference. Carbonates can be assumed to be essentially limestone. By considering the decomposition of limestone $\left(\mathrm{CaCO}_{3}\right)$ into quicklime $(\mathrm{CaO})$ and carbon dioxide, according to reaction (4), one can determine the amount of $\mathrm{CaCO}_{3}$.

$\mathrm{CaCO}_{3}(\mathrm{~s}) \rightarrow \mathrm{CaO}(\mathrm{s})+\mathrm{CO}_{2}(\mathrm{~g})$.

\subsubsection{Properties of the initial OS and of semicoke}

The properties of the initial oil shale were determined by Martins et al. [12]. They are shown in Table 1, along with the properties of semicoke determined in this work. With regard to SC, the amount of volatile matter was $0.7 \%$, which is much smaller than

Table 1

Proximate analysis of oil shale and semicoke.

\begin{tabular}{llllll}
\hline \multirow{2}{*}{ Component } & \multicolumn{7}{l}{ Proximate analysis (wt.\%) } \\
\cline { 2 - 6 } & $\mathrm{H}_{2} \mathrm{O}$ & $\mathrm{VM}$ & $\mathrm{FC}$ & $\mathrm{CaCO}_{3}$ & Inert \\
\hline Oil shale & 2.5 & 14.7 & 4.70 & 34.6 & 43.5 \\
Semicoke & - & 0.70 & 6.95 & 44.83 & 47.52 \\
\hline
\end{tabular}

the content in the oil shale: $14.6 \%$. The amount of FC in the semicoke was $7.0 \%$ and the amount of $\mathrm{CaCO}_{3}$ was determined at $44.8 \%$.

The added $\mathrm{CaCO}_{3}$ was supplied by the Provençale Company, with guaranteed purity of $99.1 \%$. A particle size range of $500-$ $2000 \mu \mathrm{m}$ was selected. The added sand was silica particles $\left(\mathrm{SiO}_{2}>90 \%\right)$ provided by Italcementi group and selected in the same particle size range by sieving. Heating the sand to $1000^{\circ} \mathrm{C}$ only induced a mass loss of $0.26 \%$. Thermogravimetric analysis was performed on the SC. The results are plotted in Fig. 3. It can be seen that the thermal decomposition of carbonates in semicoke occurs in the temperature range $550-780^{\circ} \mathrm{C}$. It has been verified from a thermogravimetric analysis that the added carbonates used in this work were decarbonated in the same temperature range.

\subsection{Fixed-bed combustion cell and parameter identification}

\subsubsection{Fixed-bed combustion cell}

Figure 4 shows the schematic diagram of the fixed-bed reactor used for the combustion tests. A detailed description of this reactor was given in [13]. Air is fed into the top of a vertical cylinder of crushed oil shale. Ignition also takes place at the top of the sample, using a cone heater that irradiates the surface through a quartz window.

During the experiments, temperatures in the bed were measured by six type-K thermocouples located along the axis of the cell at different heights (T1, T2, T3, T10, T11, and T12). A crown of six thermocouples (T4-T9) makes it possible to measure the temperature $1 \mathrm{~cm}$ away from the cell walls over a horizontal cross section: This is particularly useful to reveal whether the smoldering front progresses as a horizontal surface or not.

A new gas sampling device was added at the axis of the cell, near the bottom, in order to analyze gases. It was observed experimentally in [13] that the temperature close to the cell walls is significantly lower than that at the axis. Therefore, the medium will be less decarbonated close to the walls. The fraction of $C$ oxidized to CO may also be affected. As a consequence, the mass and energy balances at a given time should not be established over all the cell section but rather at the axis. This requires gas sampling at the cell axis. This approach represents a significant improvement in experimental procedure since the work of Martins et al. [13]. Gas analyzers were connected to the sampling device to analyze $\mathrm{CO}$ and $\mathrm{CO}_{2}$ every $4 \mathrm{~min}$ by gas chromatography and $\mathrm{O}_{2}$ using a paramagnetic analyser in a continuous mode.

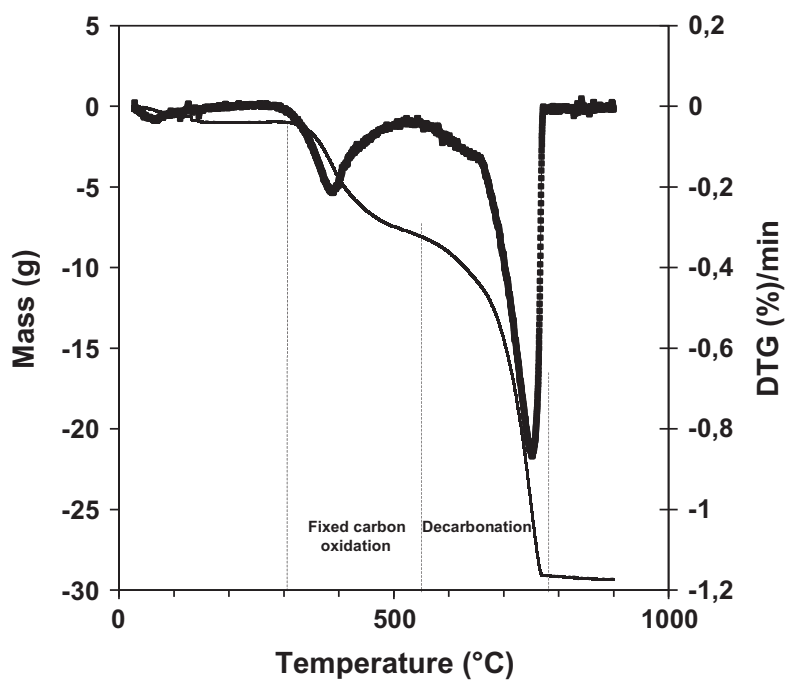

Fig. 3. TGA (light line) and DTG curves (solid line) of semicoke under air-heating at $3 \mathrm{~K} \mathrm{~min}^{-1}$ 


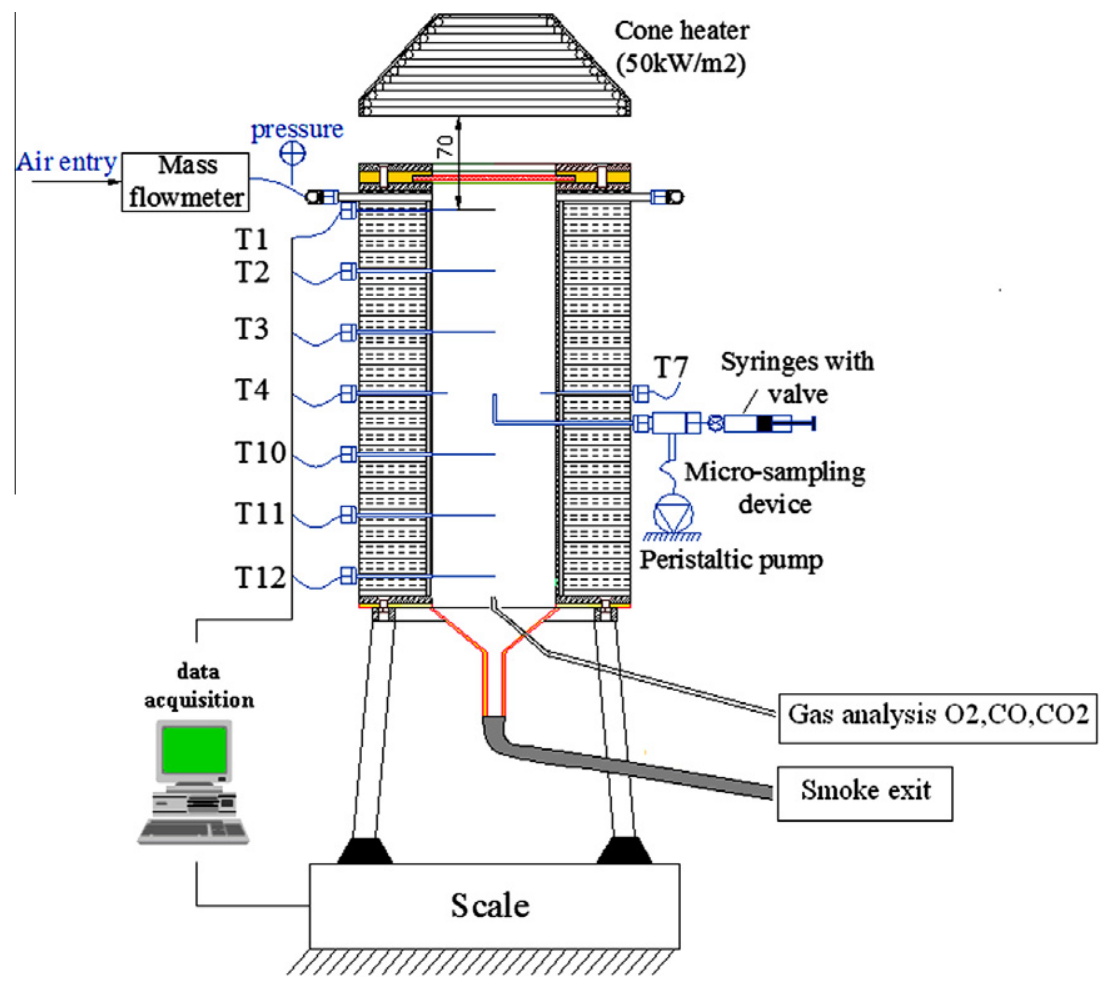

Fig. 4. Cell combustion in a porous medium, with continuous gas sampling at the axis.

To start a uniform front across the whole bed surface, a sophisticated ignition device was used, called a cone radiant heater. Since the work described in [13], the ignition protocol has been improved. An optimized air-flow rate was found to be around 12.4 $\mathrm{L} \mathrm{min}^{-1}$ at STP. A $1-\mathrm{cm}$ layer of pure semicoke was put at the top of the bed. The time of ignition was fixed at $300 \mathrm{~s}$ instead of $220 \mathrm{~s}$ in [13], with the same radiative heat flux of $50 \mathrm{~kW} \mathrm{~m}^{-2}$. These changes led to more rapid chemical front ignition and stabilization.

\subsubsection{Parameter identification}

The fraction of FC oxidized to $\mathrm{CO}$, frCO, the fraction of decarbonated carbonates, $\mathrm{fr}_{\text {decarb}}$, and the chemical front velocity, $v_{\text {frc }}$, were determined based on a mass balance for the system as detailed in
[12]. This balance was established at a time corresponding to a stabilized combustion process, i.e., in the bottom half of the cell.

- The value of frCO was adjusted by matching the balance-predicted $\mathrm{CO}$ concentration in the flue gas to the experimental value.

- The value of $\mathrm{fr}_{\text {decarb }}$ was similarly adjusted by matching the balance-predicted $\mathrm{CO}_{2}$ concentration in the flue gas to the experimental value.

- The chemical front velocity was also adjusted to match the balance-predicted total mass-loss rate to the experimental massloss rate. This was required because the derivative of the chemical front position versus time, as given by the thermocouples, was found to be insufficiently accurate for use in a mass balance approach.

Table 2

Experimental conditions and main experimental results for all experiments.

\begin{tabular}{|c|c|c|c|c|c|c|c|c|c|c|c|c|c|c|c|c|c|}
\hline & & \multirow[t]{2}{*}{ Experiment no. } & \multicolumn{3}{|c|}{ References } & \multicolumn{3}{|c|}{ Variation of $\mathrm{CaCO}_{3}$} & \multicolumn{9}{|c|}{ Variation of fixed carbon } \\
\hline & & & 1 & 2 & 3 & 4 & 5 & 6 & 7 & 8 & 9 & 10 & 11 & 12 & 13 & 14 & 15 \\
\hline \multirow{8}{*}{$\begin{array}{l}\text { Experimental } \\
\text { conditions }\end{array}$} & Mix (\% mass) & SC & & 50 & & & 50 & & & 39 & & & 30 & & & 25 & \\
\hline & & Sand & & 50 & & 40 & 30 & 0 & & 56 & & & 61 & & & 64 & \\
\hline & & $\mathrm{CaCO}_{3}$ & 0 & 50 & & 10 & 20 & 50 & & 5 & & & 9 & & & 11 & \\
\hline & & Bed density $\left(\mathrm{kg} / \mathrm{m}^{3}\right)$ & 1181 & 1170 & 1181 & 1132 & 1222 & 1165 & 1187 & 1193 & 1215 & 1214 & 1269 & 1275 & 1309 & 1261 & 1286 \\
\hline & Bed composition & VM & & 0.35 & & & 0.35 & & & 0.273 & & & 0.21 & & & 0.175 & \\
\hline & (\% mass) & Fixed carbon & & 3.475 & & & 3.475 & & & 2.71 & & & 2.085 & & & 1.73 & \\
\hline & & Carbonates & & 22.41 & & 32.41 & 42.41 & 72.41 & & 22.41 & & & 22.41 & & & 22.41 & \\
\hline & & Inert & & 73.76 & & 63.76 & 53.76 & 23.76 & & 74.60 & & & 75.29 & & & 75.68 & \\
\hline \multirow[t]{8}{*}{ Results } & Front & Temperature $\left({ }^{\circ} \mathrm{C}\right)$ & 1037 & 1004 & 1056 & 821 & 823 & 813 & 836 & 800 & 860 & 685 & 737 & 727 & 562 & 613 & 591 \\
\hline & characteristics & Velocity $(\mathrm{mm} / \mathrm{min})$ & 4.02 & 4.03 & 4.07 & 4.26 & 3.77 & 3.96 & 5.24 & - & - & 4.84 & - & - & 3.6 & - & - \\
\hline & Progress of & FC oxidation (\%) & 96.2 & 96.2 & 96.2 & 96.3 & 96.1 & 96.4 & 95 & - & - & 93.5 & - & - & 91.6 & - & - \\
\hline & reactions & frCO & 0.32 & 0.29 & 0.34 & 0.28 & 0.27 & 0.24 & 0.19 & - & - & 0.21 & - & - & 0.21 & - & - \\
\hline & & $\mathrm{CaCO}_{3}$ decarbonation (\%) & 106.5 & 93.7 & 95.2 & 88 & 69 & 37 & 58.1 & - & - & 20.4 & - & - & 7.93 & - & - \\
\hline & Vol. fraction & $\mathrm{O}_{2}$ & 0.0 & 0.0 & 0.0 & 0.0 & 0.0 & 0.0 & 0.0 & - & - & 4.72 & - & - & 10.4 & - & - \\
\hline & (\%) in flue gas & $\mathrm{CO}$ & 5.38 & 4.94 & 5.95 & 4.98 & 4.20 & 3.97 & 4.01 & - & - & 2.85 & - & - & 2.14 & - & - \\
\hline & & $\mathrm{CO}_{2}$ & 25.9 & 25.6 & 24.5 & 31.22 & 29.0 & 29.2 & 28.8 & - & - & 14.4 & - & - & 9.02 & - & - \\
\hline
\end{tabular}


Nevertheless, the three parameter identifications were coupled, since each gas species that is produced contributes to the dilution of the other species in the flue gas and changes their concentration. Moreover, $\mathrm{CO}_{2}$ is a product of decarbonation but also of carbon oxidation. Matching was therefore carried out simultaneously using a Neadler and Mead-type optimization procedure. An objective function to be minimized was calculated as the sum of the squared differences between calculation and experiments for gas species concentration and total cell mass loss rate. It was confirmed that only one set for the three identified parameters could minimize the objective function. The values found are all reported in Table 2.

\section{Results and discussion}

The experimental work was carried out as follows: a reference case was first produced using a mix of 50 mass\%/50 mass\% of SC and sand. This led to a composition of $3.48 \%$ FC and $22.4 \%$ total $\mathrm{CaCO}_{3}$. It must be noted that total $\mathrm{CaCO}_{3}$ in the mix comes from both the $\mathrm{SC}$ and the added $\mathrm{CaCO}_{3}$. The mass fraction of total $\mathrm{CaCO}_{3}$ was then varied from $22.4 \%$ to $72.4 \%$, keeping the FC at $3.48 \%$. This was achieved by adding $\mathrm{CaCO}_{3}$ and removing sand. Finally, the fraction of FC was varied from $3.48 \%$ down to $1.39 \%$ while keeping the total $\mathrm{CaCO}_{3}$ content at $22.4 \%$. The composition of all mixes is illustrated in Fig. 5, representing the mass fractions of SC, of sand and of carbonates introduced in the mixes. All experimental conditions and the main experimental results are reported in Table 2.

\subsection{Reference case}

A mix of semicoke and sand at a mass composition of 50\%/50\% was used as the reference case. The semicoke had to be mixed with sand to lower the peak temperature, which would otherwise increase beyond $1300{ }^{\circ} \mathrm{C}$ with pure SC and would lead to the formation of large aggregates in the combustion cell. All experiments in this work were carried out with an air-flow rate of $8.3 \mathrm{~L} \mathrm{~min}^{-1}$ at STP, which is equivalent to a Darcy velocity of $0.023 \mathrm{~m} \mathrm{~s}^{-1}$ at $20^{\circ} \mathrm{C}$. This velocity is the same as for the oil shale experiments carried out in [13].

Once the bed is ignited by the cone radiant heater, the smoldering front propagates continuously into the bed. Figure 6 shows the temperature evolution at several locations inside the bed. A permanent front regime was reached after the cell midheight. This was attested by the similar shape of the peaks in this part of the cell. The peak temperatures were observed to be near $1050^{\circ} \mathrm{C}$. The average value of the three bottom thermocouples is taken in the sequel of the paper as the experimental peak temperature. As shown in [13], the fact that the thermocouple temperature de- creases rapidly after the peak value is reached is due to heat losses that occur in the cell.

On the horizontal cross section at midheight of the bed (T4-T9), one can see that the peak temperature has fallen to about $900^{\circ} \mathrm{C}$ : the difference between the temperature near the wall and of the axis of the bed is about $150^{\circ} \mathrm{C}$. As mentioned in the previous paragraph, this reveals significant heat losses through the walls [13].

The time evolution of the bed mass and bed pressure drop was measured in the bed throughout the experiment and is shown in Fig. 7. The mass loss is caused by both oxidation of the FC and decarbonation of the carbonate mineral. It can be observed that the mass-loss rate (slope of the curve) increases in the first half of the experiment, and tends to a constant value in the second half.

The chemical front velocity can be calculated from the experimental data by looking at the chemical front passage at each thermocouple on the cell axis. A quadratic polynomial function giving the position of the chemical front versus time was used at the experimental points. The time derivative of this function gives an estimate of the chemical front velocity. This value was not used in this paper, as it may change during the combustion process. As explained in Section 2.2, we preferred to use the chemical front velocity determined from the parameter identification using the mass balance.

Finally, the reference-case experimental conditions were used to evaluate the repeatability of the experiment. It was reproduced three times. The three results are reported in related figures and

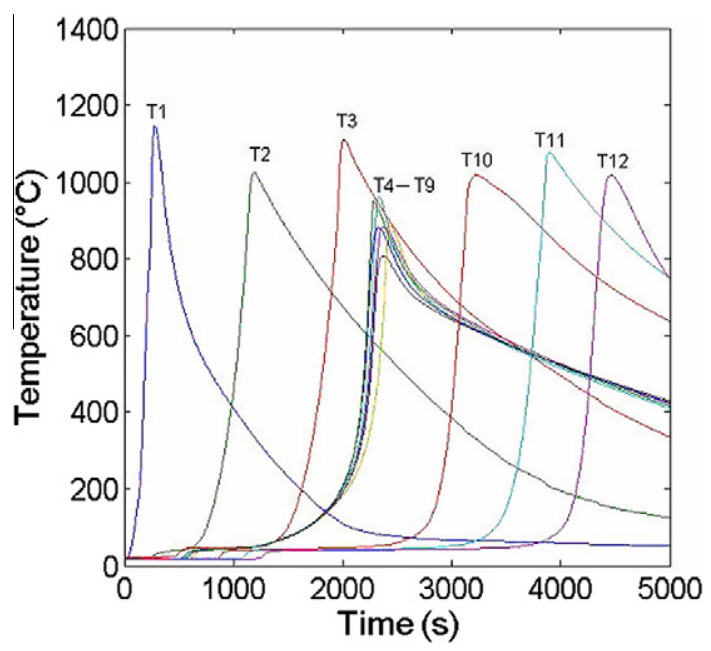

Fig. 6. Typical time evolution of temperature at several locations at the cell axis (T1, T2, T3, T10, T11, T12) and at the horizontal crown at midheight (T4-T9).

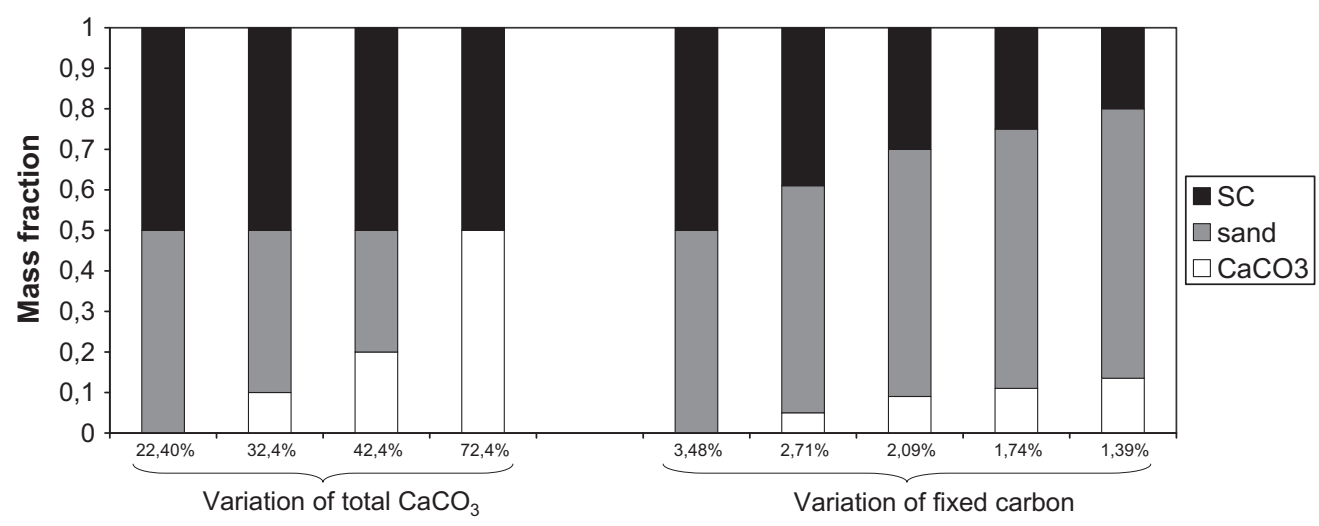

Fig. 5. SC, sand, and $\mathrm{CaCO}_{3}$ mass fractions in the different mixes used in this work. The mass fractions of $\mathrm{FC}_{\text {and }}$ total $\mathrm{CaCO}_{3}$ are indicated. 


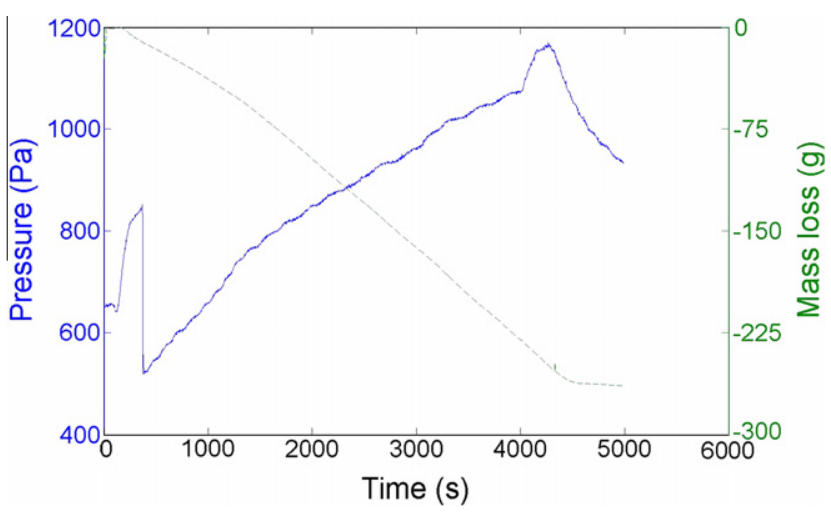

Fig. 7. Typical time evolution of the bed pressure drop (-) and of the mass loss of the bed (- -).

will give an estimate of the error in directly measured and identified parameters.

\subsection{Influence of the carbonate fraction on the peak temperature}

In this part, the amount of total $\mathrm{CaCO}_{3}$ was varied independently while the FC amount was kept at $3.48 \%$. In Fig. 8, the peak temperature is shown as a function of the total $\mathrm{CaCO}_{3}$ content. It can be seen that increasing the $\mathrm{CaCO}_{3}$ fraction in the bed from $22.4 \%$ to $32.4 \%$ reduced the front temperature from 1050 to $800^{\circ} \mathrm{C}$. Beyond that, the temperature remained stable at $800^{\circ} \mathrm{C}$ while the amount of $\mathrm{CaCO}_{3}$ was increased. Observation of the TG curve of the SC suggests some elements of interpretation. First, the curve shows that the thermal decomposition of carbonates occurs in the temperature range $550-780^{\circ} \mathrm{C}$. The decarbonation endothermic peak appears around $760{ }^{\circ} \mathrm{C}$ and stops at a characteristic temperature around $800^{\circ} \mathrm{C}$. Therefore, when the temperature is higher than $800^{\circ} \mathrm{C}, \mathrm{CaCO}_{3}$ is decarbonated rapidly. When the temperature is $800^{\circ} \mathrm{C}$ or lower, $\mathrm{CaCO}_{3}$ is not decarbonated significantly and no longer plays the role of heat sink but, instead, behaves as an inert medium. Clearly, the peak temperature can be decreased by adding a reactive endothermic medium, but not to temperatures lower than a characteristic temperature. This suggests that, by using a mineral with a lower characteristic temper-

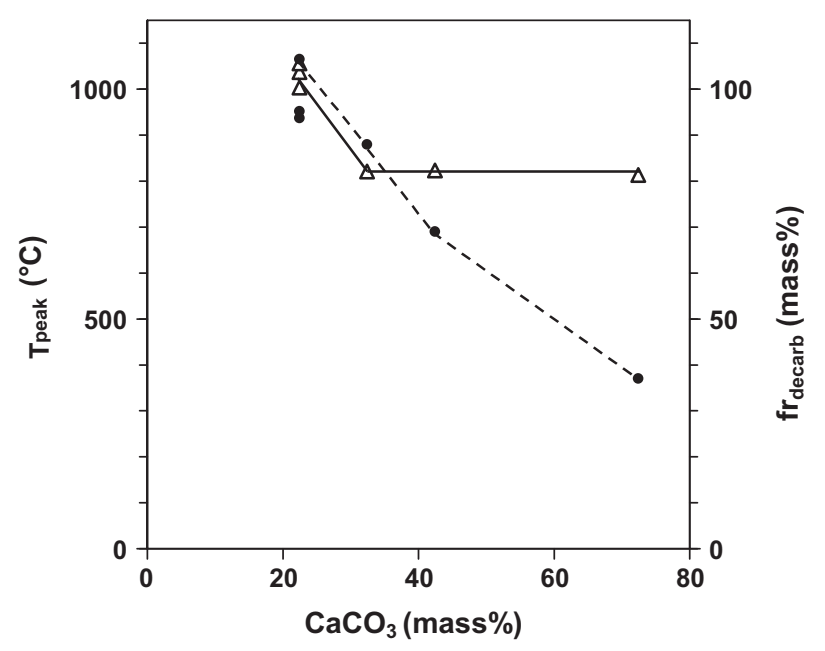

Fig. 8. Peak temperature (-) and fraction of $\mathrm{CaCO}_{3}$ decarbonated (- -) for the experiments with different amounts of total $\mathrm{CaCO}_{3}$. ature, such as kaolin or gypsum, the peak temperature could be further reduced. This interesting idea will be tested in future work.

The fraction of the initially present $22.4 \%$ of $\mathrm{CaCO}_{3}$ that was decarbonated is plotted in Fig. 8. For the reference case, all the carbonates were decarbonated. When the amount of $\mathrm{CaCO}_{3}$ was increased, the decarbonation fraction decreased, down to $37 \%$ for the experiment with $72.4 \%$ carbonates. For these experiments, it is interesting to calculate the absolute quantity of $\mathrm{CaCO}_{3}$ that is decarbonated as the product of $x_{\mathrm{CaCO}_{3}} \cdot \mathrm{fr}_{\mathrm{dec}}$. The values obtained for the three experiments with $32.4,42.4$, and $72.4 \%$ initial $\mathrm{CaCO}_{3}$ were nearly the same, i.e., $28 \pm 1 \%$ mass. It can be concluded that the chemical front can decarbonate up to $28 \% \mathrm{CaCO}_{3}$. In the reference case, as only $22.4 \%$ was present, all of it was decarbonated, while in the other cases where $\mathrm{CaCO}_{3}$ was present in quantities larger than $28 \%$ mass, only this latter quantity was converted. The remaining carbonates behaved as inert materials.

It was also observed that the chemical front velocity did not change when $\mathrm{CaCO}_{3}$ was increased, as compared to the reference case. This can be explained quite simply: at such high temperatures, the chemical front velocity is governed by the fixed carbon oxidation reaction. Indeed, almost all the FC was oxidized, as indicated by the analysis of the solid residue after combustion: only $0.25 \%$ of FC was found in the residue of all experiments. This enables us to calculate the fraction of FC that is oxidized following

$\mathrm{fr}_{\mathrm{oxi}}=\frac{\left[\rho \cdot x_{\mathrm{FC}}\right]_{\mathrm{fu}}-\left[\rho \cdot x_{\mathrm{FC}}\right]_{\mathrm{res}}}{\left[\rho \cdot x_{\mathrm{FC}}\right]_{\mathrm{fu}}}$

The values of $\mathrm{fr}_{\text {oxi }}$ are reported in Table 2. They are higher than $92 \%$.

Moreover, all the fed $\mathrm{O}_{2}$ was used, as attested by the analysis of the flue gas, which was measured to contain less than $0.1 \mathrm{~mol} \% \mathrm{O}_{2}$. This resulted in a constant chemical front velocity.

\subsection{Influence of the fixed carbon content on the peak temperature}

Figure 9 presents the effect on the front temperature of changing the bed fixed carbon content while the amount of $\mathrm{CaCO}_{3}$ remained at $22.4 \%$. These experiments were repeated three times; flue gas was analyzed only once, as reported in Table 2 . The temperature of the front decreased almost linearly from $1000^{\circ} \mathrm{C}$ down to $562{ }^{\circ} \mathrm{C}$ with the reduction in fixed carbon from $3.48 \%$ mass down to $1.73 \%$. The zone of extinction was reached during the experiment at $1.39 \%$ of fixed carbon. Ignition was good and the chemical front started to propagate through the cell. Nevertheless, the $\mathrm{O}_{2}$ fraction in the flue gas increased regularly to $20.9 \%$ and the mass loss decreased until the chemical front extinguished. This occurred at a temperature of $275^{\circ} \mathrm{C}$. This experiment was repeated and led systematically to extinction after erratic propagation. It is likely that, at a low fixed carbon fraction, the heat required for heating the medium and the heat lost from the chemical front by conduction are greater than the heat generated by carbon oxidation. Hence, the front temperature decreased and the chemical front propagation stopped. This experiment was used to draw an extinction zone in Fig. 9.

The oxygen fraction in the flue gas was analyzed and also reported in Fig. 9. It can be observed that the oxygen was totally consumed for the experiments with $3.48 \%$ mass and $2.71 \%$ FC, for which the front temperature was higher than $800^{\circ} \mathrm{C}$. This is the classic situation where the chemical front progress is controlled by oxygen supply [6]. Nevertheless, for experiments at $2.09 \%$ and $1.74 \% \mathrm{FC}$, the oxygen was only partially consumed by the fixed carbon. For the experiment at $1.74 \% \mathrm{FC}$, for which the peak temperature was $600{ }^{\circ} \mathrm{C}$, only half of the supplied $\mathrm{O}_{2}$ was consumed. Several phenomena can explain this: 


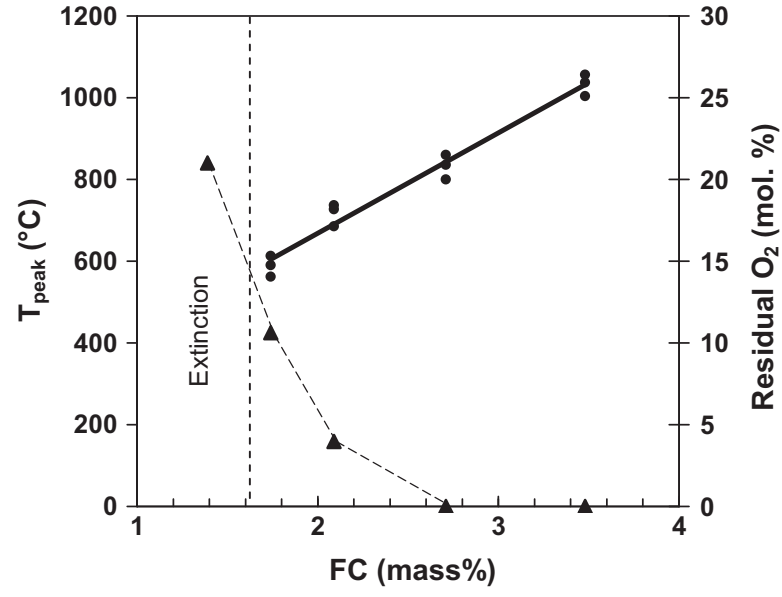

Fig. 9. Peak temperature (-) and oxygen fraction in the flue gas (- -) for the experiments with different carbon content.

(i) As the temperature decreased, the carbon oxidation kinetics slowed down. Referring to the TG curves under air in [12], one can see that the char oxidation terminated at a temperature of $550^{\circ} \mathrm{C}$. In the TG tests with a heating rate of $3 \mathrm{~K} \mathrm{~min}^{-1}$, this temperature was reached after $3 \mathrm{~h}$. Consequently, it is likely that this reaction was slow at the passage of the chemical front and not all the oxygen was consumed.

(ii) A representation of the $\mathrm{SC} / \mathrm{sand} / \mathrm{CaCO}_{3}$ particles in the medium may give another clue to interpretation. Figure 10 describes schematically a cross section of the porous medium that respects the particle-size ratio of 4 between the larger and the smaller particles and the proportions of the three components in the mix, here distinguished using different gray levels. Part A of the figure represents the reference case. It can be seen that the reactive particles, i.e., SC particles, are quite close to each other. In the case of the experiment with $1.74 \% \mathrm{FC}$, which is represented in part B of the figure, reactive particles are much more dispersed. One can imagine that bypasses may exist, as large as the chemical front thickness, through which $\mathrm{O}_{2}$ can advect without the opportunity to diffuse to the surface of a reactive particle. This thickness has been estimated to be several grain sizes in [13] and is illustrated by the $6 \mathrm{~mm}$ scale in the figure. This effect is likely to play a role in the partial consumption of $\mathrm{O}_{2}$.
A consequence of the fact that not all $\mathrm{O}_{2}$ was consumed by the chemical front should be that its velocity would decrease. Indeed, in the case where all $\mathrm{O}_{2}$ was consumed and all $\mathrm{FC}$ oxidized, the chemical front velocity was inversely proportional to the carbon content. It was first checked that all the initially present FC was oxidized by analyzing the solid residue: only $0.25 \%$ FC was found, even for experiments where the front temperature was low and not all oxygen consumed. Ohlemiller [6] reported that low temperatures generally reflect the fact that smoldering causes incomplete oxidation of the carbon in the fuel. This is not the case in this work. The equation of the line in Fig. 11 is $v_{\mathrm{frc}}=k / x_{\mathrm{FC}}$, with $k=13.9 \mathrm{~mm}$ $\min ^{-1} \%$. It corresponds to the case where all FC is oxidized and all oxygen consumed, since in this situation the product $v_{\mathrm{frc}} \cdot x_{\mathrm{FC}}$ that expresses the mass flow rate of oxidized carbon is proportional to the fed oxygen flow rate, which was constant for all experiments. The constant $k$ was adjusted to fit the experimental points with the higher $\mathrm{FC}$ content, for which all $\mathrm{O}_{2}$ was actually consumed. It can be noted that the curve also fits the experiment at $2.71 \%$ FC. For the experiment at $2.09 \%$ FC and even more for the one at $1.74 \% \mathrm{FC}$, the measured chemical front velocities are much lower than the theoretical ones, as represented by the line. This suggests that the nonconsumption of $\mathrm{O}_{2}$ by the chemical front is responsible for front slowdown. It can be observed that the slowdown is proportional to the nonconsumed $\mathrm{O}_{2}$.

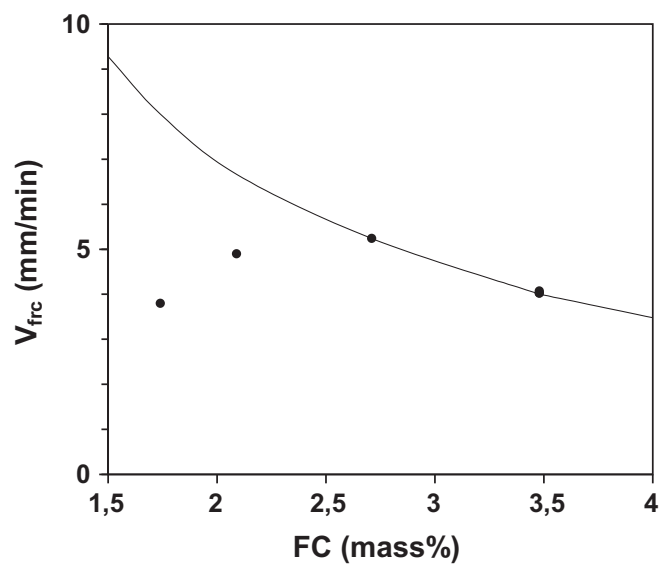

Fig. 11. Experimental values of the chemical front velocity for experiment with different FC content $(\bullet)$ and theoretical evolution if all $\mathrm{O}_{2}$ were consumed (- -)
$50 \%$ semi-coke $50 \%$ sand

$25 \%$ semi-coke $64 \%$ sand $11 \%$ carbonates

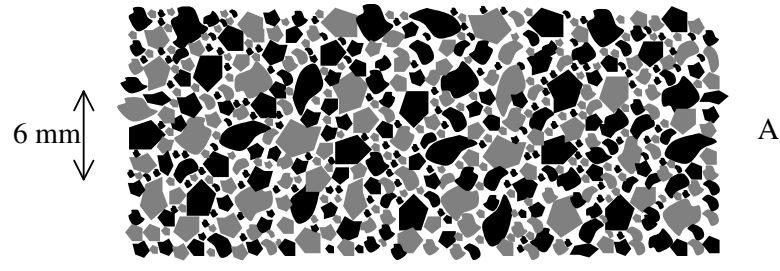

$\mathrm{O} 2$

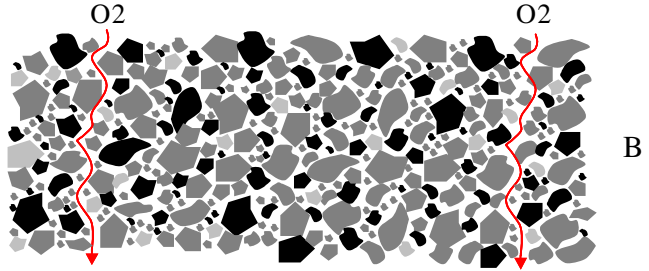

Fig. 10. A representation of the porous medium respecting the smaller/larger particle-size ratio and the proportions of $\mathrm{SC}$, sand, and $\mathrm{CaCO}_{3}$, in $(\mathrm{A})$ : the reference experiment and (B): the experiment at $1.74 \%$ FC. 
If one plots the decarbonated fraction of the $22.4 \%$ carbonate minerals initially present versus the peak temperature, as illustrated in Fig. 12, one can observe that this fraction progressively increases with the peak temperature. At $562{ }^{\circ} \mathrm{C}$, only $8 \%$ of the carbonates are decarbonated. This value is one of the main conclusions of the present work: after the SC is diluted so that the amount of FC is $1.73 \%$, the front temperature falls to $562{ }^{\circ} \mathrm{C}$, and only $8 \%$ of the $\mathrm{CaCO}_{3}$ is decarbonated. It is therefore possible to avoid most of the decarbonation of the medium. Nevertheless, these conditions result in the use of only half of the fed oxygen. The case of the front at $685^{\circ} \mathrm{C}$ obtained with a FC amount of $2.09 \%$ may also be interesting for practical applications: $81 \%$ of the oxygen is used by the chemical front, while $21.2 \%$ of the $\mathrm{CaCO}_{3}$ is decarbonated.

\subsection{Investigation into the fraction of fixed carbon oxidized to $\mathrm{CO}$}

As discussed in Section 1, the frCO parameter-the fraction of FC that is oxidized to $\mathrm{CO}-$ has a strong influence on the chemical front velocity and temperature. From all the results presented above, it is possible to plot its value as a function of the front temperature (Fig. 12). This figure represents the experimental fraction of FC oxidized to $\mathrm{CO}(--)$ versus the peak temperature, for all the experiments carried out in this work. It indicates that frCO varied between 0.19 and 0.35 . Despite significant dispersion, the values tend to indicate an increase of frCO with temperature. This result is in agreement with the literature about carbon oxidation: increasing temperature leads to increasing yields in CO [26-29]. We believe that the frCO parameter plays the role of temperature controller. Indeed, with experimental conditions corresponding to a high fraction of FC, which would tend to create a high temperature front, frCO increases and moderates the temperature. If for some reason the front temperature tends to decrease, frCO also decreases and contributes to an increase in the temperature. Therefore, these phenomena may contribute to increasing the stability of the chemical front.

The quantitative values obtained here are of practical interest. It is shown that only approximately $30 \%$ of the FC is oxidized to CO. There is thus potentially another alternative to decreasing the front temperature: increasing frCO. As shown from the theoretical study in this work, an increase in frCO by 0.1 decreases the plateau temperature by more than $300^{\circ} \mathrm{C}$. Feeding the chemical front with a $\mathrm{CO}_{2}$-rich gas could be an alternative way of reaching this objective. Indeed, adding $\mathrm{CO}_{2}$ to the incoming gas would lead to an increase in the $\mathrm{CO}_{2}$ partial pressure in the smoldering front. This may favor

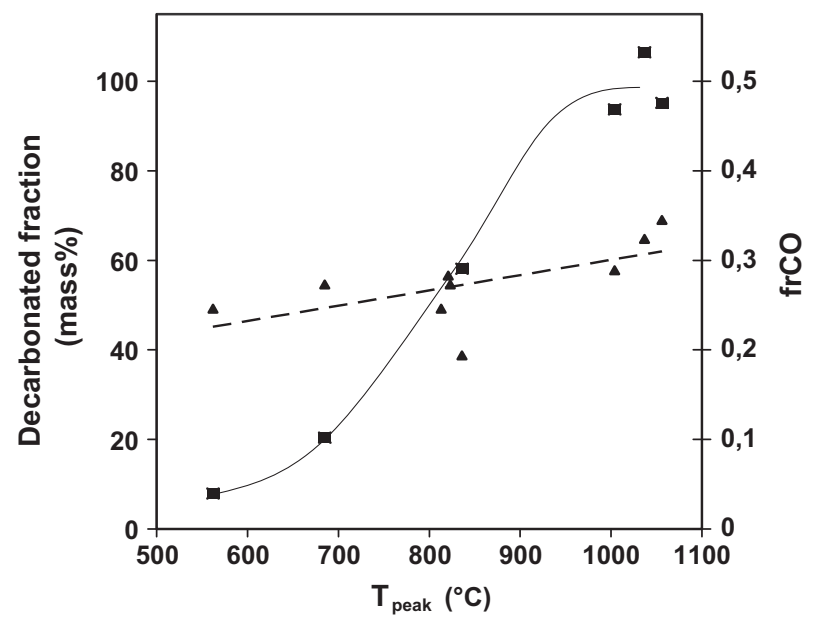

Fig. 12. Decarbonated fraction versus peak temperature (-) and experimental fraction of FC oxidized to $\mathrm{CO}$ versus plateau temperature (- -).

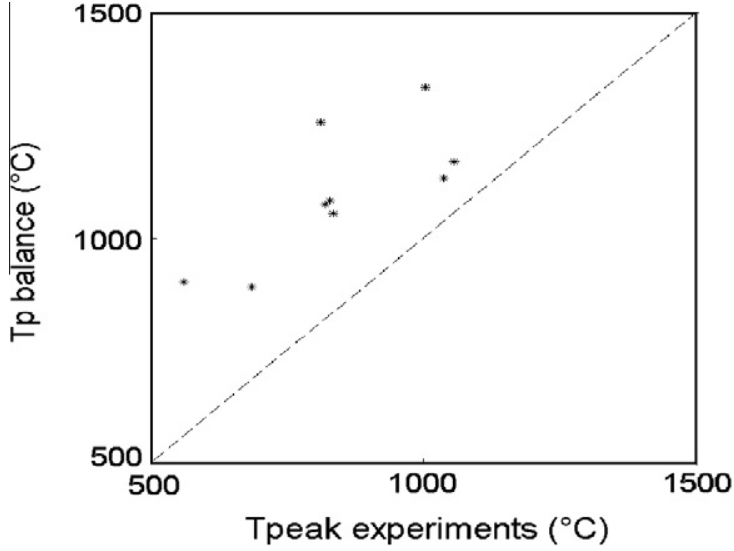

Fig. 13. Balance-predicted plateau temperature versus the experimentally-measured peak temperature.

the oxidation of $\mathrm{C}$ to $\mathrm{CO}$ considering that the Boudouard reaction $\mathrm{C}+\mathrm{CO}_{2} \rightarrow 2 \mathrm{CO}$ will be favored. This may also limit the $\mathrm{CaCO}_{3}$ decarbonation reaction $[31,32]$.

This original technique, contrary to mixing with inert or reactive solids, may find applications for in situ combustion. It will be tested in future work.

\subsection{Capacity of the simplified energy balance to predict the peak temperature}

This section evaluates the capacity of the energy balance-as described in the Introduction-to predict the experimental peak temperature. To this purpose, we have plotted in Fig. 13 the balance-predicted plateau temperature versus the experimental peak temperature. It can be seen that the energy-balance results capture the general trends of the experiments but cannot accurately predict the peak temperature. This confirms the literature reporting that energy balances provide only poor agreements with actual smoldering temperatures.

\section{Conclusions and perspectives}

The temperature of the smoldering front is clearly influenced by the composition of fixed carbon and inert/reactive solid in the porous medium. The increasing of the $\mathrm{CaCO}_{3}$ content caused a reduction in the front temperature from $1050^{\circ} \mathrm{C}$ to $800^{\circ} \mathrm{C}$, but not below. At this temperature, $\mathrm{CaCO}_{3}$ is still decarbonated, and to the same level of $28 \%$ of the mix mass, whatever the carbonate's initial quantity. The remaining carbonates behave as an inert material.

The temperature of the smoldering front was decreased from $1050{ }^{\circ} \mathrm{C}$ to $562{ }^{\circ} \mathrm{C}$ by decreasing fixed carbon from $3.48 \%$ to $1.73 \%$. At $1.39 \%$ of fixed carbon, the chemical front extinguishes. At $562{ }^{\circ} \mathrm{C}$, the chemical front propagates and decarbonates only $8 \%$ of the $\mathrm{CaCO}_{3}$ present. Only half of the fed oxygen is consumed by the chemical front, which slows down proportionally to the nonutilized oxygen. This is probably due to slow carbon oxidation kinetics or, maybe, to the fact that the reactive particles are so dispersed that $\mathrm{O}_{2}$ can flow through the oxidation zone without reacting.

Whatever the experimental conditions, even at the lower temperatures, only $0.25 \%$ of fixed carbon is left in the medium after the passage of the chemical front. It was found that $19 \%$ to $35 \%$ of fixed carbon was oxidized into CO. This fraction tends to increase with the front temperature and, consequently, may act as 
a front temperature controller that increases the front stability. Feeding the chemical front with a $\mathrm{CO}_{2}$-rich gas-using a recovered $\mathrm{CO}_{2}$ for instance-is one perspective revealed by this study. It may increase the fraction of FC oxidized to $\mathrm{CO}$, and decrease the front temperature in in situ applications.

This study thus offers promising methods to process oil shale or semicoke without degrading part of the mineral matter, typically responsible of $70 \%$ of $\mathrm{CO}_{2}$ emissions. These results present an initial approach to cold-front propagation. This approach can be generalized to include other porous media, and opens perspectives on using other reactive solids such as kaolin or gypsum as temperature moderators.

\section{Acknowledgment}

The authors are most grateful to Bernard Auduc for his technical support during all experiments.

\section{Appendix A}

Calculation of the plateau temperature from an energy balance over a smoldering front: case $\delta<1$.

A representation of a smoldering front in the $\delta<1$ mode is given in Fig. 14. A general case is considered here, in which the virgin medium called fuel will form smoke during combustion of $\mathrm{FC}$ and $\mathrm{CO}_{2}$ due to decarbonation of the mineral matrix. These reactions are assumed to occur at the chemical front. The chemical front travels at velocity $v_{\text {frc }}$ higher than the thermal velocity $v_{\text {frt }}$, i.e.,

$\delta=\frac{v_{\mathrm{frt}}}{v_{\mathrm{frc}}}<1$.

\section{A.1. Chemical front velocity $v_{f r c}$}

The velocity of the chemical front can be calculated from a balance on $\mathrm{O}_{2}$ species, expressing that the molar flux density consumed by the reaction equals the molar flux transported by air [6].

The molar flux density of $C$ oxidized by the chemical front is (in mole $\mathrm{s}^{-1} \mathrm{~m}^{-2}$ )

$\frac{v_{\mathrm{frc}} \rho_{\mathrm{fu}} x_{\mathrm{FC}} \mathrm{fr}_{\mathrm{oxi}}}{M_{\mathrm{C}}}$.

The fixed carbon oxidation to $\mathrm{CO}$ and $\mathrm{CO}_{2}$ is written

$\mathrm{C}+\left[\frac{\mathrm{frCO}}{2}+(1-\mathrm{frCO})\right] \mathrm{O}_{2} \rightarrow \mathrm{frCOCO}+(1-\mathrm{frCO}) \mathrm{CO}_{2}$.

Therefore the oxidation of $1 \mathrm{~mol}$ of $C$ requires $1-\mathrm{frCO} / 2 \mathrm{~mol}$ of $\mathrm{O}_{2}$, and the molar flux density of $\mathrm{O}_{2}$ required by the chemical front can be expressed as (in mole $\mathrm{s}^{-1} \mathrm{~m}^{-2}$ )

$\frac{v_{\mathrm{frc}} \rho_{\mathrm{fu}} x_{\mathrm{FC}} \mathrm{fr}_{\mathrm{oxi}}}{M_{\mathrm{C}}}\left(1-\frac{\mathrm{frCO}}{2}\right)$.

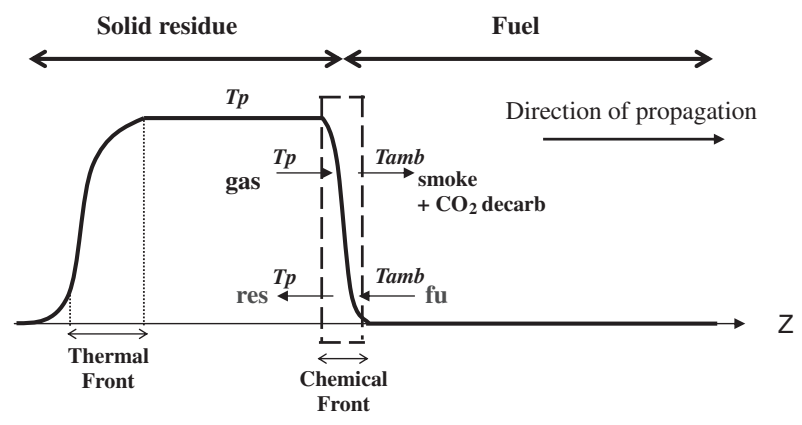

Fig. 14. Temperature profile in the reaction leading structure $\delta<1$.
The molar flux density of air fed to the chemical front is

$\frac{v_{\mathrm{g}} \rho_{\mathrm{g}}}{M_{\mathrm{g}}}$,

and using the molar fraction of $\mathrm{O}_{2}$ in the air $y_{\mathrm{O}_{2}}$, the molar flux density of $\mathrm{O}_{2}$ fed to the chemical front is

$\frac{v_{\mathrm{g}} \rho_{\mathrm{g}}}{M_{\mathrm{g}}} y_{\mathrm{O}_{2}}$.

From Eqs. (A.3) and (A.5), we have

$v_{\mathrm{frc}}=\frac{v_{\mathrm{g}} \rho_{\mathrm{g}}}{M_{\mathrm{g}}} y_{\mathrm{O}_{2}} \frac{M_{\mathrm{C}}}{\rho_{\mathrm{fu}} x_{\mathrm{FC}} \mathrm{fr}_{\mathrm{oxi}}\left(1-\frac{\mathrm{frCO}}{2}\right)}$.

\section{A.2. Thermal front velocity $v_{f r t}$}

A thermal balance over the thermal front can be written as

$$
\begin{aligned}
& \dot{m}_{\mathrm{g}} C p_{\mathrm{g}}\left(T_{\mathrm{p}}-T_{\text {ref }}\right)+\dot{m}_{\text {res }} C p_{\text {res }}\left(T_{\mathrm{amb}}-T_{\text {ref }}\right)-\dot{m}_{\text {res }} C p_{\text {res }}\left(T_{\mathrm{p}}-T_{\text {ref }}\right) \\
& \quad-\dot{m}_{\mathrm{sm}} C p_{\mathrm{sm}}\left(T_{\mathrm{amb}}-T_{\text {ref }}\right)=0,
\end{aligned}
$$

where $T_{\text {ref }}$ is a reference temperature. The calorific value for SC and solid residue was fixed at $830 \mathrm{~J} \mathrm{~kg}^{-1} \mathrm{~K}^{-1}$

Taking $T_{\mathrm{amb}}$ for the reference temperature leads to

$\dot{m}_{\mathrm{g}} C p_{\mathrm{g}}\left(T_{\mathrm{p}}-T_{\mathrm{amb}}\right)-\dot{m}_{\text {res }} C p_{\text {res }}\left(T_{\mathrm{p}}-T_{\mathrm{amb}}\right)=0$,

where

$\dot{m}_{\mathrm{g}}=\rho_{\mathrm{g}}\left(v_{\mathrm{g}}-v_{\mathrm{frt}}\right)$

and, since we have $v_{\mathrm{frt}} \ll v_{\mathrm{g}}$,

$\dot{m}_{\mathrm{g}}=\rho_{\mathrm{g}} v_{\mathrm{g}}$

$\dot{m}_{\text {res }}=\rho_{\text {res }} v_{\text {frt }}$.

Then we may write

$v_{\text {frt }}=\frac{\rho_{\mathrm{g}} v_{\mathrm{g}} C p_{\mathrm{g}}}{\rho_{\text {res }} C p_{\text {res }}}$,

where $\rho_{\text {res }}$ is the volumetric mass of the solid residue that can be calculated as the sum of the volumetric mass of the residual $\mathrm{CaCO}_{3}$, of the formed $\mathrm{CaO}$ and the inert minerals.

$\rho_{\text {res }}=\rho_{\text {fu }}\left[x_{\mathrm{CaCO}_{3}}\left(1-\mathrm{fr}_{\text {decarb }}\right)+x_{\mathrm{CaCO}_{3}} \mathrm{fr}_{\mathrm{decarb}} \frac{M_{\mathrm{CaO}}}{M_{\mathrm{CaCO}_{3}}}+x_{i n}\right]$.

\section{A.3. Plateau temperature}

The thermal balance over the chemical front can be written as

$$
\begin{aligned}
& \dot{m}_{\mathrm{g}} C p_{\mathrm{g}}\left(T_{\mathrm{p}}-T_{\mathrm{ref}}\right)+\dot{m}_{\mathrm{fu}} C p_{\mathrm{fu}}\left(T_{\mathrm{amb}}-T_{\mathrm{ref}}\right)+\dot{m}_{\mathrm{FC}} \Delta H_{\mathrm{FC}} \\
& \quad+\dot{m}_{\mathrm{CaCO}_{3}} \Delta H_{\mathrm{CaCO}_{3}}-\dot{m}_{\mathrm{sm}} C p_{\mathrm{sm}}\left(T_{\mathrm{amb}}-T_{\mathrm{ref}}\right) \\
& \quad-\dot{m}_{\mathrm{CO}_{2} \text { decarb }} C p_{\mathrm{CO}_{2} \text { decarb }}\left(T_{\mathrm{amb}}-T_{\text {ref }}\right)-\dot{m}_{\text {res }} C p_{\text {res }}\left(T_{\mathrm{p}}-T_{\text {ref }}\right)=0 .
\end{aligned}
$$

Taking $T_{\mathrm{amb}}$ as the reference temperature leads to

$$
\begin{aligned}
& \left(T_{\mathrm{p}}-T_{\mathrm{amb}}\right)\left(\dot{m}_{\mathrm{g}} C p_{\mathrm{g}}-\dot{m}_{\mathrm{res}} C p_{\mathrm{res}}\right) \\
& =-\left(\dot{m}_{\mathrm{CaCO}_{3}} \Delta H_{\mathrm{CaCO}_{3}}+\dot{m}_{\mathrm{FC}} \Delta H_{\mathrm{FC}}\right),
\end{aligned}
$$

or

$T_{\mathrm{p}}=\frac{\dot{m}_{\mathrm{CaCO}_{3}} \Delta H_{\mathrm{CaCO}_{3}}+\dot{m}_{\mathrm{FC}} \Delta H_{\mathrm{FC}}}{\dot{m}_{\mathrm{res}} C p_{\mathrm{res}}-\dot{m}_{\mathrm{g}} C p_{\mathrm{g}}}+T_{\mathrm{amb}}$,

where

$\dot{m}_{\mathrm{FC}}=v_{\mathrm{frc}} \rho_{\mathrm{fu}} x_{\mathrm{FC}}$, 
$\dot{m}_{\mathrm{CaCO}_{3}}=v_{\mathrm{frc}} \rho_{\mathrm{fu}} x_{\mathrm{CaCO}_{3}} \mathrm{fr}_{\mathrm{decarb}}$,

$\dot{m}_{\mathrm{g}}=\left(v_{\mathrm{g}}-v_{\mathrm{frc}}\right) \rho_{\mathrm{g}}$,

since we have $v_{\text {frc }} \ll v_{\text {g, }}$, then $\dot{m}_{g}=v_{\mathrm{g}} \rho_{\mathrm{g}}$ and

$\dot{m}_{\text {res }}=v_{\text {frc }} \rho_{\text {res }}$.

This equation is of the same nature and basis as that developed by Dosanjh et al. [30].

\section{A.4. Heats of reaction}

Fixed carbon oxidation reaction may be written

$\mathrm{C}+(1-\mathrm{frCO}) \mathrm{O}_{2} \rightarrow \mathrm{frCO} \mathrm{CO}+(1-\mathrm{frCO}) \mathrm{CO}_{2}$

According to Hess's law, we have (with our sign definition)

$\Delta H_{\mathrm{FC}}=110.5 \mathrm{frCO}+396.5(1-\mathrm{frCO}) \mathrm{kJ} / \mathrm{mol}$.

The decarbonation reaction may be written

$\mathrm{CaCO}_{3} \rightarrow 0.56 \mathrm{CaO}+0.44 \mathrm{CO}_{2}$.

According to Hess's law, we have (with our sign definition)

$\Delta H_{\mathrm{CaCO}_{3}}=-635.1-393.5+1207=+178.4 \mathrm{~kJ} / \mathrm{mol} \mathrm{CaCO}$.

\section{Appendix B}

\begin{tabular}{ll}
\multicolumn{2}{c}{ Nomenclature } \\
Physical & Meaning \\
symbol & \\
fp & calorific capacity $(\mathrm{J} / \mathrm{kg} \mathrm{K})$ \\
$\mathrm{fr}$ & fraction \\
$\mathrm{frCO}$ & fraction of $\mathrm{FC}$ oxidized into CO \\
$k$ & constant \\
$\varepsilon$ & porosity \\
$m$ & mass $(\mathrm{g})$ \\
$M$ & molar mass $(\mathrm{g} / \mathrm{mol})$ \\
$\dot{m}$ & mass flow rate in the front frame $(\mathrm{kg} / \mathrm{s})$ \\
$T$ & temperature $\left({ }^{\circ} \mathrm{C}\right)$ \\
$v$ & velocity $(\mathrm{m} / \mathrm{s})$ \\
$x$ & mass fraction \\
$y$ & molar fraction \\
$\delta$ & ratio between thermal and chemical front \\
$\Delta H$ & velocities \\
Greek symbol & reaction heat $(\mathrm{J} / \mathrm{mol})$ \\
$\rho$ & volumetric mass $\left(\mathrm{kg} / \mathrm{m}^{3}\right)$ \\
Subscript & \\
Materials & \\
fu & fuel \\
$\mathrm{g}$ & gas \\
OS & oil shale \\
SC & semicoke \\
S & solid \\
&
\end{tabular}

$\begin{array}{ll}\text { Sm } & \text { smoke } \\ \text { res } & \text { solid residue } \\ \mathrm{C} & \text { carbon } \\ \mathrm{CaCO}_{3} & \begin{array}{l}\text { calcium carbonate } \\ \text { fixed carbon }\end{array} \\ \mathrm{FC} & \text { inert } \\ \text { in } & \\ \text { Reactions } & \text { decarbonated } \\ \text { decarb } & \text { devolatilized } \\ \text { dev } & \text { oxidized carbon } \\ \text { oxi } & \\ \text { Others } & \text { chemical front } \\ \text { frc } & \text { thermal front } \\ \text { frt } & \text { plateau } \\ \text { p } & \end{array}$

\section{References}

[1] M.V. Kök, J. Thermal. Anal. Calorim. 68 (2005) 1061

[2] X.X. Han, X.M. Jiang, Z.G. Cui, J. Therm. Anal. Calorim. 92 (2008) 595-600.

[3] A. Kahru, L. Põllumaa, Oil Shale 23 (2006) 53-93.

[4] W. Qing, S. Baizhong, W. Xiahua, B. Jingru, S. Jian, Oil Shale 23 (2006) 328-339.

[5] I. Külaots Indrek, L.G. Jillian, E.M. Suuberg, Fuel 89 (2010) 3300-3306.

[6] T.J. Ohlemiller, Prog. Energy Combust. Sci. 11 (1985) 277-319.

[7] A.P. Aldushin, B.S. Seplyarsky, Theory of Filtration Combustion of Porous Metallic Specimens, OIKhF, USSR Academy of Sciences, Chernogolovka, 1977.

[8] D.A. Schult, B.J. Matkowsky, V.A. Volpert, A.C. Fernandez-Pello, Combust. Flame 101 (1996) 471-490.

[9] A.A.M. Oliviera, M. Kaviani, Prog. Energy Combust. Sci. 27 (2001) 623-645.

[10] H. Thunman, Bo Leckner, Fuel 82 (2003) 275-283.

[11] A.G. Merzhanov, B.I. Khaikin, Prog. Energy Combust. Sci. 14 (1988) 1-98.

[12] M.F. Martins, S. Salvador, J.F. Thovert, G. Debenest, Fuel 89 (2010) 144-151.

[13] M.F. Martins, S. Salvador, J.F. Thovert, G. Debenest, Fuel 89 (2010) 133-143.

[14] M. Elayeb, Modélisation à l'échelle microscopique de transports avec réaction en milieu poreux: combustion en lit fixe, Ph.D. Thesis, Université de Poitiers, France, 2008.

[15] D. Shin, T. Yu, W. Yang, B. Jeon, S. Park, J. Hwang, Waste Manage. 28 (2008) 2422-2427.

[16] P. Pironi, C. Switzer, G. Rein, A. Fuentes, J.I. Gehard, J.L. Torero, Proc. Combust. Inst. 32 (2009) 1957-1964.

17] J.P. Vantelon, B. Lodeho, S. Pignoux, J.L. Ellzey, J.L. Torero, Proc. Combust. Inst. 30 (2005) 2239-2246.

[18] H. Zhou, A.D. Jensen, P. Glarborg, P.A. Jensen, A. Kavaliauskas, Fuel 84 (2005) 389-403.

[19] H. Fang, N. Zobel, Z. Wenjian, F. Behrendt, Biomass Bioenergy 33 (2009) 10191029.

[20] R. Changkook, A.N. Phan, Y.B. Yang, V.N. Sharifi, J. Swithenbank, Waste Manage. 27 (6) (2007) 802-810.

[21] Z.Y. Miao, G.G. Wu, P. Li, N. Zhao, P.C. Wang, X.L. Meng, Mining Sci. Technol (China) 3 (2009) 380-384.

22] X.M. Jiang, X.X. Han, Z.G. Cui, Prog. Energy Combust. Sci. 33 (2007) 552-579.

[23] T. Kaljuvee, R. Kuusik, A. Trikkel, N. Maljukova, Oil Shale 20 (2003) 113-125.

[24] Q. Wang, H. Wang, B. Sun, J. Bai, X. Guan, Fuel 88 (2009) 1520-1529.

[25] H. Arro, A. Prikk, T. Pihu, I. Opik, Oil Shale 19 (2002) 117-125.

26] N.M. Laurendeau, Prog. Energy Combust. Sci 4 (1978) 221-270.

[27] L. Tgnotti, J.P. Longwell, A.F. Sarofim, in: Twenty-Third Symposium (International) on Combustion. The Combustion Institute, Pittsburgh, 1990, pp. 1207-1213.

[28] R.E. Mitchell, Combust. Sci. Technol. 53 (1987) 165-186.

[29] T.F. Zeng, F. WB, Combust. Flame 107 (1996) 197-210.

[30] S.S. Dosanjh, P.J. Pagni, A.C. Fernandez-Pello, Combust. Flame 68 (1987) 131142.

[31] T.R. Ingraham, R.H. Marier, Can. J. Chem. Eng. (1963) 170-173.

[32] J. Khinast, G.F. Krammer, C. Brunner, G. Staudinger, Chem. Eng. Sci. 4 (1996) 623-634. 